\title{
A statistical survey of the composition of gallstones in eight countries
}

\author{
D. JUNE SUTOR AND SUSAN E. WOOLEY \\ From the Department of Chemistry, University College, London
}

SUMmARY The crystalline composition of gallstones from Australia, England, Germany, India, Kuwait, South Africa, Sweden, and the USA has now been determined by the $x$-ray powder method. Eleven compounds were identified. The three cholesterols-cholesterol monohydrate, anhydrous cholesterol, and cholesterol II-account for $71 \%$ of the total crystalline material in the stones; the calcium carbonates -vaterite, aragonite, and calcite-contribute $15 \%$, and calcium palmitate contributes $6 \%$. Smaller amounts of apatite, sodium chloride, whitlockite, and $\alpha$-palmitic acid were also found. The composition distribution in each country is significantly different. Gallstones from Germany, Sweden, and Australia are the most similar. Gallstones from England have significantly more carbonate, and stones from South Africa have much less cholesterol and more calcium phosphate and calcium palmitate. Stones from Kuwait have a large amount of calcium palmitate and those from India an excess of calcium phosphate. The composition of stones related to the age and to the sex of a patient shows that although there are no significant differences in composition for patients under and over the age of 50 there are differences in the stone composition related to the patient's sex. Female patients form much more cholesterol while males form much more calcium palmitate and slightly more calcium carbonate. The differences also exist for female and male patients over and under 50 years of age. A study of the texture and orientation of the crystalline material in the gallstones has shown that anhydrous cholesterol and cholesterol monohydrate can occur as single crystals oriented with respect to the nucleus whereas other stone components are disoriented crystallites.

In a recent paper (Sutor and Wooley, 1969) we reported the crystalline composition of biliary calculi from English and Australian patients as determined by the $x$-ray powder method. This work formed a preliminary investigation in a project designed to relate, if possible, the crystalline material present in gallstones to any other available data such as the patient's age, sex, or country of domicile. The crystalline composition of gallstones from Germany, India, Kuwait, South Africa, Sweden, and the USA has subsequently been determined. The results are presented here together with a statistical survey carried out on all available relevant data for the eight countries concerned.

\section{Material}

The 331 stones included in the survey came from Received for publication 9 September 1970. the following countries: Australia (21 stones), England (47), Germany (50), India (19), Kuwait (36), South Africa (26), Sweden (45), and the USA (87). The gallstones were usually collected in sequence over a period of several months as the patients presented for operation. The stones from Germany, however, represent every sixth one taken from a large collection. Information on the patient's age and sex was not available for every stone; in particular the ages of the Indian patients are unknown.

\section{Method}

IDENTIFICATION OF CRYSTALLINE

MATERIAL

The different crystalline compounds present in the gallstones were identified by the $x$-ray powder method. The principle and use of this technique have been described in the previous paper (Sutor 
and Wooley, 1969). Specimens from the stones for $x$-ray photography were obtained by splitting the gallstones in half and taking samples from the exposed surfaces. If the stone had a definite structure such as a layered one, samples were taken first from the nucleus (this area gives information on conditions prevailing when the stone initially formed), second from the intermediate layer (more than one sample was taken if this were not homogeneous), and third from the surface. If, on the other hand, the stone seemed uniform in texture and composition with no apparent nucleus, either one sample was taken or one from the interior and one from the surface. The specimens were lightly powdered and photographed using filtered copper radiation and a Nonius Guinier-type camera. This camera gives good resolution of the diffraction lines, usually enabling components of mixtures to be identified and making differentiation between two similar forms of cholesterol possible (Fig. 1). The diffraction patterns were matched against standard ones of the constituents we have identified in gallstones. These are reproduced in Figure 1. The $d$-spacings and relative intensities of the lines on these photographs are listed by the following authors: calcite, aragonite, apatite, and whitlockite by Sutor and Scheidt (1968), cholesterol monohydrate by Bogren and Larsson (1963), and anhydrous cholesterol, vaterite, sodium chloride, and $\alpha$-palmitic acid in the ASTM (American Society for Testing and Materials) powder diffraction file. Data for cholesterol II and the form of calcium palmitate found in gallstones which have not been reported previously were calculated from our photographs and are listed in Table I. These are the only crystalline compounds present. Some papers have given calcium oxalate as a constituent of gallstones and in one case it was reputedly identified by $x$-ray diffraction (Raha, Sen Gupta, and Aikat, 1966). The published photographs show, however, that the compound is cholesterol monohydrate. Calcium oxalate does not occur in bile and its presence in gallstones is not physiologically possible.

The components of mixed samples from gallstones can usually be identified readily because the different diffraction patterns have very few lines in common (Fig. 1) and masking of a minor component by a major one is unlikely to occur. The only difficulties are in differentiating between anhydrous cholesterol and cholesterol II in the presence of an equal amount or excess of cholesterol monohydrate and in identifying small

\begin{tabular}{|c|c|c|c|}
\hline \multicolumn{2}{|c|}{ Cholesterol II } & \multicolumn{2}{|c|}{ Calcium Palmitate } \\
\hline $\mathrm{d}(A)$ & I & $\mathrm{d}(A)^{1}$ & $\mathbf{I}$ \\
\hline $\begin{array}{l}33 \cdot 4 \\
16 \cdot 9 \\
13 \cdot 6 \\
11 \cdot 18 \\
9 \cdot 13 \\
8 \cdot 39 \\
8 \cdot 20 \\
7 \cdot 76 \\
6.76 \\
6.69 \\
6 \cdot 46 \\
6 \cdot 02 \\
5 \cdot 62 \\
5 \cdot 51 \\
5 \cdot 28 \\
5 \cdot 15 \\
5 \cdot 01 \\
4 \cdot 92 \\
4 \cdot 53 \\
4 \cdot 10\end{array}$ & $\begin{array}{l}\text { Very strong } \\
\text { Medium weak } \\
\text { Weak } \\
\text { Very weak } \\
\text { Very weak } \\
\text { Very weak } \\
\text { Weak } \\
\text { Very weak } \\
\text { Weak } \\
\text { Very weak } \\
\text { Weak } \\
\text { Weak } \\
\text { Strong } \\
\text { Medium weak } \\
\text { Strong } \\
\text { Strong } \\
\text { Medium weak } \\
\text { Medium } \\
\text { Weak } \\
\text { Weak }\end{array}$ & $\begin{array}{r}23 \cdot 0 \\
15 \cdot 2 \\
11 \cdot 25 \\
9 \cdot 00 \\
6 \cdot 42 \\
5 \cdot 83 \\
5 \cdot 71 \\
5 \cdot 46 \\
5.21 \\
4.90 \\
4.40 \\
4 \cdot 35 \\
4 \cdot 10 \\
4 \cdot 03 \\
3 \cdot 85 \\
3 \cdot 39 \\
3 \cdot 34 \\
3 \cdot 28 \\
2 \cdot 90\end{array}$ & $\begin{array}{l}\text { Strong } \\
\text { Very strong } \\
\text { Medium weak } \\
\text { Medium } \\
\text { Very weak } \\
\text { Weak } \\
\text { Very weak } \\
\text { Very weak } \\
\text { Very weak } \\
\text { Very weak } \\
\text { Very strong } \\
\text { Very strong } \\
\text { Medium } \\
\text { Medium } \\
\text { Weak } \\
\text { Medium } \\
\text { Weak } \\
\text { Very weak } \\
\text { Weak }\end{array}$ \\
\hline
\end{tabular}

Table I Interplanar spacings (d) and intensities (I) for the lines on the powder patterns of cholesterol II and calcium palmitate

${ }^{1}$ The $d$-spacings may be subject to a small error in origin since an internal standard was not used in making the measurements.

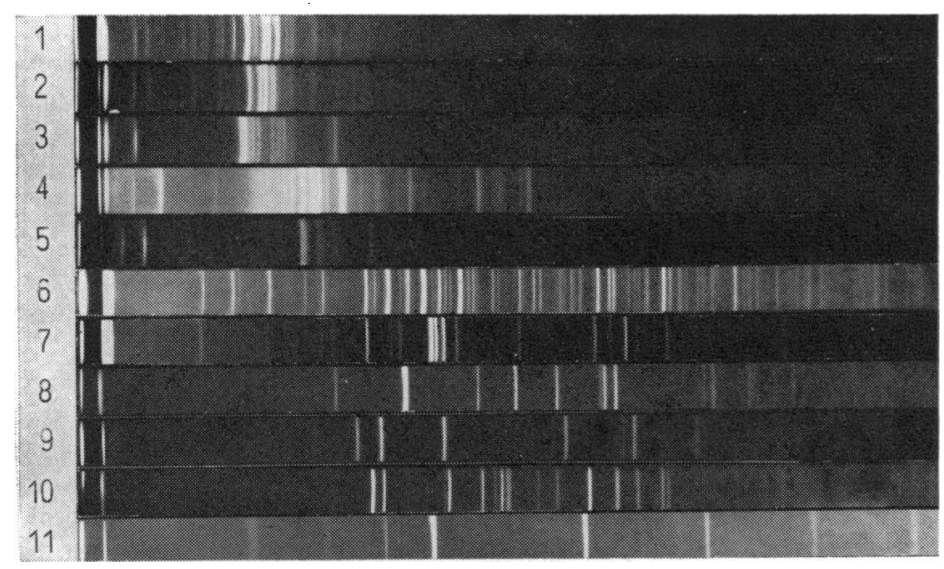

Fig. 1 X-ray powder photographs of constituents of gallstones. The photographs were taken on a Nonius Guinier-type camera (camera radius, $57.3 \mathrm{~mm}$ ).

$1=$ cholesterol, $2=$ cholesterol II, 3 = cholesterol monohydrate, $4=\alpha$-palmitic acid, $5=$ calcium palmitate, $6=$ whitlockite, $7=$ apatite, $8=$ calcite, $9=$ vaterite $10=$ aragonite, $11=$ sodium chloride. 


\begin{tabular}{|c|c|c|c|c|c|c|}
\hline \multirow[t]{2}{*}{ Minor Constituent } & \multicolumn{6}{|c|}{ Major Constituent } \\
\hline & Apatite & Calcite & Sodium Chloride & Calcium Palmitate & Anhydrous Cholesterol & $\alpha$-Palmitic Acid \\
\hline Apatite & & 3 & $\sim 15$ & 3 & 1 & 1 \\
\hline Calcite & 1 & & 5 & 1 & 0.5 & 0.5 \\
\hline Sodium chloride & 5 & $\sim 3$ & & $\sim 4$ & 2 & 1 \\
\hline Calcium palmitate & $\sim 4$ & 5 & 5 & & $\overline{2}$ & 2 \\
\hline Anhydrous cholesterol & 5 & 7 & 7 & 2 & & 3 \\
\hline$\alpha$-Palmitic acid & 2 & 1 & 1 & 1 & 2 & \\
\hline
\end{tabular}

Table IIa The percentage of a compound which can be just identified in the presence of a major constituent for representatives of the different groups of gallstone components

\begin{tabular}{|c|c|}
\hline Constituent & $\begin{array}{l}\text { Absorption } \\
\text { Coefficient }(\mu)\end{array}$ \\
\hline Anhydrous cholesterol & $4 \cdot 5$ \\
\hline $\begin{array}{l}\text { Cholesterol monohydrate } \\
\text { Cholesterol } \mathbf{I I}^{\mathbf{1}}\end{array}$ & $4 \cdot 8$ \\
\hline $\begin{array}{l}\text { Cholesterol } \mathbf{I I}^{\mathbf{1}} \\
\text { Calcite }\end{array}$ & $\sim 4.6$ \\
\hline $\begin{array}{l}\text { Calcite } \\
\text { Aragonite }\end{array}$ & $192 \cdot 1$ \\
\hline Aragonite & $209 \cdot 1$ \\
\hline Vaterite & $187 \cdot 8$ \\
\hline Calcium palmitate ${ }^{1}$ & $\sim 32$ \\
\hline$\alpha$-Palmitic acid & $4 \cdot 2$ \\
\hline Apatite & $262 \cdot 1$ \\
\hline Whitlockite & 258.4 \\
\hline Sodium chloride & $130 \cdot 2$ \\
\hline
\end{tabular}

Table IIb Absorption coefficients ( $\mu$ ) for the constituents for $\mathrm{CuK \alpha}$ radiation

${ }^{1}$ The density used in the calculation of $\mu$ is not accurately known.

amounts of apatite in the presence of sodium chloride. The minimum amount of a minor component of a mixture which can be detected is variable because of large differences in the absorption coefficient for $x$ rays of the different compounds present in gallstones (Table II). For two component systems the minimum observable amount varies from $0.5 \%$ to $15 \%$ but is usually around $2 \%$. Most of the high percentages occur in detecting small quantities of material in the presence of sodium chloride. As this compound is only present in small traces these mixtures are not found in practice.

\section{TEXTURE AND ORIENTATION OF}

\section{GALLSTONE CONSTITUENTS}

Samples from different gallstones were also examined to determine the texture and orientation of the different crystalline components. The specimen (say about $0.5 \mathrm{~mm}$ linear dimensions) was mounted without any further preparation on the tip of a glass fibre and placed in a 'singlecrystal' camera so that a known direction was vertical, for example, the direction that had been radial in the stone. The sample could then be rotated about the vertical axis and photographed again with filtered radiation. If the specimen consisted of a random array of crystallites the $x$-ray photographs would show the continuous rings typical of a disorientated powder. If the material had some preferred orientation in it, the rings would be broken up into arcs and if the specimen were a single crystal only discrete spots would be present on the photograph.

\section{CALCULATION OF STONE COMPOSITION}

From the intensity of the diffraction patterns a quantitative estimation was made of the relative amount of material present in mixed samples. Each component identified in a stone was then weighted according to the amount found in the different areas. The scheme adopted is described in the previous paper (Sutor and Wooley, 1969). The values were then averaged over the whole collection to obtain the weighted percentage composition. The method has certain advantages over presenting the results in terms of major stone components which has often been used previously, since it shows that collections contain observable quantities of a compound although it may never occur in that collection as a major component. Although the method does not give the quantitative composition of the gallstones exactly, it is a good approximation to the relative amounts of the various constituents present.

\section{STATISTICAL SURVEY}

The data on the weighted percentage composition of a stone, the patient's age, sex, country, etc, were punched on cards, one card being devoted to each patient. Because of the relatively small number of stones examined only two age groups were considered: first, patients 50 years of age and under, and second, patients over the age of 50 . The first group includes three females and two males under 21 years of age. An IBM 360 computer was then used to classify and correlate combinations of the data for the statistical calculations. Statistical significance was tested using the chi-square test. 


\section{Results}

NUMBER OF STONES RELATED TO THE

PATIENT'S SEX OR AGE

The distribution of stones in the various countries according to first the sex, and second the age, of a patient is shown in Table III. The overall pattern of more female to male cases is the same in each area $(P>0.05)$ and the total number of female patients significantly exceeds the number of male ones $(P<0.001)$ by about 5 to 2 . In each country the pattern is more patients at operation over the age of $50(P>0.05)$ except in the USA where there is the same number in each group and in Kuwait where the reverse is true.

Comparison of the patient's age and sex for Australia, England, Germany, Sweden, and South Africa confirms the above observations. In Kuwait there are more patients of both sexes in the younger age group and the age to sex ratio in the country is consistent ( $P>0.05)$. In the USA there are significantly more female patients in the younger age group compared with the older one $(\mathrm{P}<0.03)$.

\section{CONSTITUENTS OF THE GALLSTONES}

Of the 331 stones studied, about a third consist of a single crystalline substance or of a mixture of different forms or hydrates of a compound. The number of different kinds of pure stones is listed in Table IV. The remaining stones are of mixed composition.

The compounds identified and their relative abundance in the stones are given in Table $\mathrm{V}$ and discussed below.

\section{Cholesterols}

Three forms of cholesterol have been found: anhydrous cholesterol (by far the most abundant compound), cholesterol monohydrate, and another form which we have called cholesterol II. Altogether they account for $71 \%$ of the total crystalline material found in the stones (Table V). Ninety-three per cent of the stones which have observable nuclei have cholesterol in this region. Once it is laid down in a stone subsequent regions almost invariably contain observable amounts. One hundred and two of the pure stones belong to the cholesterol group. Of these 54 are of anhydrous cholesterol, 12 of cholesterol monohydrate, and 36 of a mixture of different cholesterols. Anhydrous cholesterol and cholesterol monohydrate are readily interchangeable, suggesting that water can enter and leave the lattices without difficulty. Because of this reaction and studies made on cholesterol deposits freshly removed from man which showed that the material was invariably cholesterol monohydrate (Bogren and Larsson, 1963), it seems that anhydrous cholesterol is originally laid down as the monohydrate. As far as is known, the much less common form, cholesterol II, reported by Sutor and Wooley, in 1969, has not been found by other workers. Chemically the compound has not yet been completely characterized. It may be another form of anhydrous cholesterol or it may

\begin{tabular}{lrccc}
\hline Country & Male & Female & $\leqslant 50$ Years & $>50$ Years \\
\hline Australia & 7 & 13 & 5 & 14 \\
England & 18 & 28 & 13 & 32 \\
Germany & 9 & 41 & 18 & 32 \\
India & 6 & 12 & & \\
Kuwait & 8 & 26 & 29 & 5 \\
South Africa & 8 & 15 & 4 & 13 \\
Sweden & 9 & 28 & 15 & 24 \\
USA & 25 & 62 & 34 & 34 \\
Total & 90 & 225 & 118 & 154 \\
\hline
\end{tabular}

Table III Number of stones related to sex and age

\begin{tabular}{ll}
\hline Constituent(s) & No. of Stones \\
\hline Anhydrous cholesterol & 54 \\
Cholesterol monohydrate & 12 \\
Mixed cholesterols & 36 \\
Aragonite & 2 \\
Mixed calcium carbonates & 7 \\
Calcium palmitate & 5 \\
Apatite & 1 \\
Mixed calcium phosphates & 1 \\
Amorphous material & 8 \\
Unidentified material & 4 \\
\hline
\end{tabular}

Table IV Number of pure stones

\begin{tabular}{lc}
\hline Constituent & Amount (\%) \\
\hline Composition of all stones & \\
Cholesterol & $71 \cdot 0$ \\
Calcium carbonate & $15 \cdot 2$ \\
Calcium palmitate & $6 \cdot 0$ \\
Calcium phosphate & $2 \cdot 8$ \\
Others & $5 \cdot 0$ \\
& \\
Contribution of individual constituents & \\
Anhydrous cholesterol & $52 \cdot 3$ \\
Cholesterol monohydrate & $16 \cdot 0$ \\
Vaterite & $6 \cdot 4$ \\
Calcium palmitate & $5 \cdot 9$ \\
Aragonite & $4 \cdot 6$ \\
Calcite & $4 \cdot 1$ \\
Amorphous material & $3 \cdot 1$ \\
Cholesterol II & $2 \cdot 7$ \\
Apatite & $2 \cdot 4$ \\
Unidentified material & $1 \cdot 0$ \\
Sodium chloride & $0 \cdot 9$ \\
Whitlockite & $0 \cdot 4$ \\
Palmitic acid & $0 \cdot 1$ \\
lat
\end{tabular}

Table $\mathrm{V}$ Relative abundance of the constituents in all the gallstones 
contain a small amount of water of crystallization in the lattice. Crystallographically it is very similar to anhydrous cholesterol and the two compounds can only be distinguished by using a high resolution camera (Fig. 1). Cholesterol II usually occurs with one or both of the other forms of cholesterol but frequently it is the sole constituent of samples from freshly removed gallstones. Some evidence suggests that it can change very slowly into anhydrous cholesterol. There are two possible modes of formation of cholesterol II: first by the decomposition of cholesterol monohydrate under suitable conditions and secondly by direct precipitation from bile. Data given in Table VI, which lists the different compounds that can grow directly on each other in gallstones of mixed composition, do not differentiate between the two possibilities. Work is still in progress on the composition and formation of cholesterol II.

\section{Calcium carbonates}

The three forms of calcium carbonate-vaterite, aragonite, and calcite- have been identified. As a group they rank next to the cholesterols and contribute $15 \%$ of the crystalline material in the stones (Table V). Vaterite is the most abundant compound after anhydrous cholesterol and cholesterol monohydrate. It accounts for $43 \%$ of the total calcium carbonate, aragonite accounts for $30 \%$, and calcite for $27 \%$. This distribution is unusual in that calcite has frequently been reported in nature but aragonite and particularly vaterite are much less common forms. There are two stones in the collection consisting of pure aragonite (both from male patients) and seven of a mixture of calcium carbonates.

\section{Calcium palmitate $\left(\left[\mathrm{CH}_{3}\left(\mathrm{CH}_{2}\right)_{14} \mathrm{COO}\right]_{2} \mathrm{Ca}\right)$ and $\alpha$-palmitic acid $\left(\mathrm{CH}_{3}\left(\mathrm{CH}_{2}\right)_{14} \mathrm{COOH}\right)$}

These two compounds account for $6 \%$ of the total crystalline material (Table V). Previous to our work, fatty acids have only been reported in gallstones from Japan. The calcium salts were found by chemical analysis, calcium palmitate was identified by $x$-ray diffraction (see references in Bogren, 1964), and a quantitative chemical analysis showed that some stones contained a large amount of palmitic acid but the exact form or compound was not known (Nakayama, 1968). Our work represents the first positive identification of $\alpha$-palmitic acid in gallstones and the first report of calcium palmitate in gallstones from countries other than Japan (Sutor, 1970). Calcium palmitate must have been overlooked by other workers since it occurs in $36 \%$ of the stones studied here and it is the fourth most abundant com-

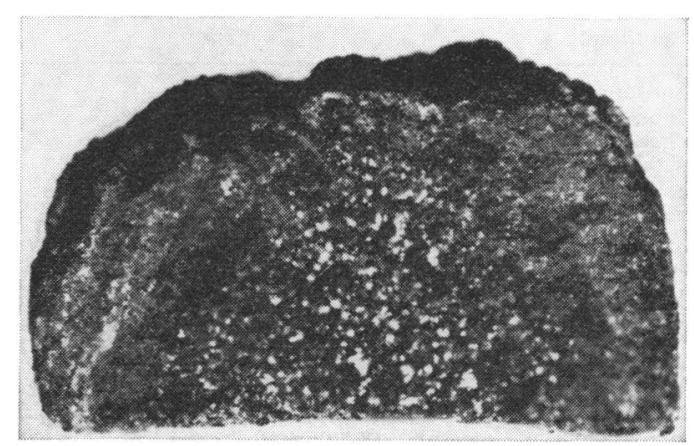

Fig. 2. White 'beads' of calcium palmitate scattered over the cut surface of part of a stone consisting of a mixture of anhydrous cholesterol, calcite, and vaterite. Dimensions approximately $2 \times 1.1 \mathrm{~cm}$.

pound ranking next to vaterite. Five pure calcium palmitate stones were found. In 18 other stones it is a major component and in another 16 it occurs as a minor component. In 70 stones, including 16 already mentioned, calcium palmitate is present as small white spheroids scattered through the stones but frequently forming only a small part of them (Fig. 2). These spheroids have been appropriately described as 'beads' (Sutor and Wooley, 1969; Sutor, 1970). $\alpha$-Palmitic acid is a rare compound and occurs in only three stones all from female patients.

\section{Calcium phosphates}

The two forms of calcium phosphate, apatite $\left(\mathrm{Ca}_{10}\left(\mathrm{PO}_{4}\right)_{6}(\mathrm{OH})_{2}\right)$ and whitlockite $\left(\beta-\mathrm{Ca}_{3}\left(\mathrm{PO}_{4}\right)_{2}\right)$, which are found in gallstones, make up $2.8 \%$ of the crystalline material (Table V). Apatite frequently occurs in a finely divided form which gives only a diffuse $x$-ray pattern. Its presence can therefore be difficult to detect by this method and could well have been overlooked. Both carbonateand hydroxy-apatite are formed in nature. These are only distinguishable by a simple chemical test for carbonate and because calcium carbonate is a constituent of gallstones, the form of apatite present cannot be determined. Whitlockite is a rare compound and occurs in only three of the stones (all from female patients). One of the pure stones consists entirely of apatite and another of a mixture of apatite and whitlockite.

\section{Amorphous material}

The presence of amorphous material could only be detected if a sample gave no $x$-ray diffraction pattern. The figure of $3.1 \%$ (Table $\mathrm{V}$ ) is therefore an underestimate of the total amount of non- 


\begin{tabular}{lll}
\hline Constituent & Code & Substances which Can Grow on Reference Compound \\
\hline Anhydrous cholesterol & L1 & L2, L3, M1, M2, M3, Q, R, R as a bead, F2, F4, amorphous material \\
Cholesterol monohydrate & L2 & L1, L3, M1, M2, M3, P, R, R as a bead \\
Cholesterol II & L3 & L1, L2, M2, R \\
Calcite & M1 & L1, L2, M2, M3, R(?), F2, amorphous material \\
Aragonite & M2 & L1, L2, M1, R \\
Vaterite & M3 & L2 \\
a-Palmitic acid & Q & L1, R \\
Sodium chloride & R & L1, L2, L3, M1(?), M2, M3, Q, R as a bead, F2, F4 \\
Calcium palmitate & R (as a bead) & L1, L2, R, F2 \\
Calcium palmitate (as a bead) & F2 & L1, M1, R, R as a bead, F4 \\
Apatite & F4 & L1, R, F2 \\
Whitlockite & & L1, M1 \\
Amorphous material & &
\end{tabular}

Table VI Compounds which can grow directly on the different constituents of gallstones

diffracting material present. Eight stones consist entirely of amorphous material. In five of the other six stones where nondiffracting material was detected, it is present in the nucleus. In one instance the amorphous material was shown to be calcium phosphate by chemical analysis (Sutor and Wooley, 1969). The other stones and samples may consist of calcium phosphate or bile pigments. No bile pigments were found in this study. They are therefore amorphous or present in such small amounts as to be undetectable.

\section{Unidentified material}

Under this heading are grouped the occasional unidentified line(s) occurring in a diffraction pattern and a completely unknown pattern obtained from a few stones which might have resulted from material absorbed from a solution in which the stones had been washed or soaked. The pattern occurs in the collection from Kuwait.

\section{Sodium chloride}

This compound has been frequently identified in gallstones. As it is soluble in bile, its presence in the stones is likely to be an artifact. In practically every instance in this study, sodium chloride was only found in stones containing anhydrous cholesterol. Frequently gallstones are soaked in saline solution on removal and the presence of sodium chloride is attributed to absorption of this compound onto the stone or possibly into the lattice of anhydrous cholesterol. Work is still in progress on this theory but so far sodium chloride has not been found in stones which are purposely not being soaked in saline solution on removal.

\section{TEXTURE AND ORIENTATION OF}

CRYSTALLINE MATERIAL IN GALLSTONES

Both cholesterol and cholesterol monohydrate can occur in gallstones as single crystals and these are orientated with respect to the nucleus, that is to say, a prominent crystallographic axis lies along the radial direction of the stone. All the other components were found to occur as disorientated crystallites having no preferred orientation. In this respect gallstones are unlike urinary calculi in which preferred orientation of the compounds frequently occurs (Carr, 1953; Sutor, unpublished data).

\section{COMPOUNDS DIRECTLY ASSOCIATED WITH}

\section{OTHER GALLSTONE CONSTITUENTS}

The components which can grow directly on other constituents of stones under favourable conditions are summarized in Table VI. The data were compiled from the composition of two component samples and from adjacent samples consisting of single compounds. Combinations other than these may be possible but could not be deduced from our data. Lonsdale (1968) postulated that close epitaxial relationships between the stone constituents might play a part in the growth of stones of mixed composition. Calculations of the dimensions of prominent crystal faces showed that anhydrous cholesterol, calcite, aragonite, vaterite, and apatite should be able to grow on each other. Apart from sodium chloride, the crystal structures of the other stone components are not known and calculations involving these compounds could not be made. Data presented in Table VI, which provides experimental evidence to test the theory, confirm some of the calculations. Not all of the calculated combinations have been observed in this study but, as mentioned previously, this does not preclude their possibility. A complete evaluation of the role of epitaxy is not possible until the crystal structures of the other stone components are known.

COMPOSITION OF STONE NUCLEI

Only 158 stones have observable nuclei. The weighted percentage composition of this area in 


\begin{tabular}{|c|c|c|c|c|c|c|}
\hline Country & No. of Stones & Cholesterol & Calcium Carbonate & Calcium Phosphate & Calcium Palmitate & Others \\
\hline Australia & 5 & 93 & $3 \frac{1}{2}$ & - & - & $3 \frac{1}{2}$ \\
\hline England & 11 & 66 & $17^{2}$ & - & - & $17^{2}$ \\
\hline Germany & 40 & 90 & 3 & 3 & 3 & 1 \\
\hline India & 12 & 69 & 6 & 17 & 2 & 6 \\
\hline Kuwait & 10 & 60 & 14 & 14 & 9 & 3 \\
\hline South Africa & 11 & 66 & 8 & - & 21 & 5 \\
\hline Sweden & 27 & 94 & 2 & 2 & - & 2 \\
\hline USA & 42 & 88 & 5 & - & 4 & 3 \\
\hline All & 158 & 84 & 6 & 3 & 4 & 3 \\
\hline
\end{tabular}

Table VII Weighted percentage composition of the nuclei of 158 stones from eight countries

the different countries is given in Table VII. In calculations to test statistical significance in both this section and subsequent ones dealing with whole stones, the different forms of cholesterol, calcium carbonate, and calcium phosphate have usually been grouped under their general names and the remaining minor components have been classified together. This was necessary so as to take into account the fact that the cholesterols are interchangeable and to reduce the number of parameters involved in the calculations since the number of stones examined is not large. A comparison of the composition in each country indicates significantly more calcium carbonate in England and Kuwait, significantly more calcium phosphate in India and Kuwait, significantly more calcium palmitate in South Africa, and significantly more of the remaining compounds (mainly amorphous material) in England $(P<0.001)$. To a certain extent this distribution reflects the composition of the whole stones but not completely (see next section). Comparison of the composition of the nucleus with that of the rest of the stone shows that in every country the two differ significantly from each other $(P<0.001)$. For all the stones there is significantly more apatite and amorphous material and significantly

\begin{tabular}{lll}
\hline Compound & \multicolumn{2}{l}{ Percentage Composition } \\
\cline { 2 - 3 } & Nucleus & Interior and Surface \\
\hline Anhydrous cholesterol & 20.99 & 39.43 \\
Cholesterol monohydrate & $6 \cdot 13$ & 10.41 \\
Cholesterol II & 0.80 & 2.22 \\
Calcite & $0 \cdot 52$ & 3.13 \\
Aragonite & 0.54 & $2 \cdot 15$ \\
Vaterite & 0.85 & 5.90 \\
a-Palmitic acid & 0.02 & 0.02 \\
Sodium chloride & 0.36 & 0.35 \\
Calcium palmitate & $1 \cdot 27$ & $2 \cdot 29$ \\
Apatite & 1.02 & 0.45 \\
Unidentified material & 0.14 & 0.07 \\
Amorphous material & 0.69 & 0.24 \\
\hline
\end{tabular}

Table VIII Weighted percentage composition of the nucleus compared with the interior and surface for 158 gallstones less calcium carbonate, particularly vaterite and calcite, in the nuclei (Table VIII).

COMPOSITION OF THE WHOLE STONE

RELATED TO COUNTRY OF DOMICILE, AGE, OR SEX OF A PATIENT

The weighted percentage composition of the collections from different countries in terms of all observable constituents and the percentage number of stones containing an observable amount of a particular compound are given in Table IX. The figures for the percentage occurrence of the constituents indicate that quite a high proportion of the stones contain observable amounts of the calcium carbonates, calcium palmitate, and apatite although, as reference to the weighted percentage composition shows, these amounts are small in comparison with that of cholesterol. The weighted percentage composition classified in terms of only the major components is presented diagrammatically for the various countries in

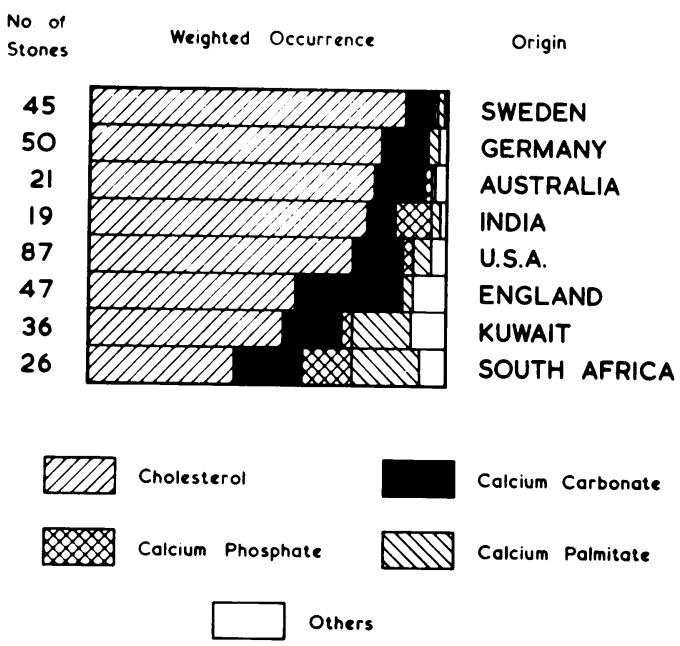

Fig. 3. The weighted percentage composition of gallstones from eight countries. 


\begin{tabular}{|c|c|c|c|c|c|c|c|c|c|c|c|c|c|c|}
\hline \multirow[t]{2}{*}{ Country } & \multirow{2}{*}{$\begin{array}{l}\text { No. of } \\
\text { Gallstones }\end{array}$} & \multicolumn{13}{|c|}{ Component } \\
\hline & & $L 1$ & $L 2$ & $L 3$ & MI & M2 & M3 & $\boldsymbol{P}$ & $\boldsymbol{Q}$ & $\boldsymbol{R}$ & $F 2$ & $F 4$ & $\begin{array}{l}\text { Amorphous } \\
\text { Material }\end{array}$ & $\begin{array}{l}\text { Unidentified } \\
\text { Lines }\end{array}$ \\
\hline \multicolumn{15}{|c|}{ Weighted percentage occurrence } \\
\hline Australia & 21 & 77 & 1 & 2 & 4 & 1 & 9 & - & 3 & 1 & 1 & 1 & - & 1 \\
\hline England & 47 & 26 & 29 & 3 & 8 & 12 & 10 & 1 & 3 & 2 & $>0$ & - & 5 & 1 \\
\hline Germany & 50 & $75 \frac{1}{2}$ & 5 & $1 \frac{1}{2}$ & 2 & 4 & 6 & - & 1 & 3 & 1 & - & 2 & - \\
\hline India & 19 & $64^{2}$ & $12 \frac{1}{8}$ & $1 \frac{2}{2}$ & $3 \frac{1}{2}$ & $2 \frac{1}{8}$ & 2 & - & - & $2 \frac{1}{8}$ & 10 & - & 1 & - \\
\hline Kuwait & 36 & $48 \frac{1}{2}$ & $2 \frac{1}{8}$ & 31 & $4 \frac{2}{8}$ & 3 & 9 & - & 1 & $16 \frac{1}{8}$ & 3 & - & $2 \frac{1}{2}$ & 6 \\
\hline South Africa & 26 & 22 & 18 & 1 & $10^{3}$ & 3 & 6 & - & 1 & $19^{3}$ & 14 & - & $4^{2}$ & 2 \\
\hline Sweden & 45 & $67 \frac{1}{8}$ & 21 & 一 & $1 \frac{1}{2}$ & 2 & 5 & - & $\frac{1}{2}$ & 2 & $\frac{1}{8}$ & - & - & - \\
\hline USA & 87 & $49^{\circ}$ & 20 & 5 & 3 & 5 & 6 & $>0$ & $>0$ & 5 & 1 & 2 & 5 & $>0$ \\
\hline \multicolumn{15}{|c|}{ Percentage occurrence } \\
\hline Australia & 21 & 100 & 10 & 25 & 30 & 5 & 40 & - & 15 & 20 & 5 & 5 & - & 5 \\
\hline England & 47 & 50 & 54 & 13 & 35 & 33 & 41 & 2 & 8 & 15 & 4 & - & 6 & 13 \\
\hline Germany & 50 & 96 & 22 & 14 & 22 & 18 & 36 & - & 12 & 32 & 4 & - & 2 & 2 \\
\hline India & 19 & 95 & 26 & 16 & 10 & 16 & 16 & - & - & 16 & 26 & - & 5 & - \\
\hline Kuwait & 36 & 78 & 3 & 42 & 36 & 14 & 44 & - & 17 & 47 & 17 & - & 6 & 17 \\
\hline South Africa & 26 & 58 & 35 & 8 & 42 & 19 & 38 & - & 8 & 35 & 27 & - & 12 & 15 \\
\hline Sweden & 45 & 82 & 33 & - & 16 & 9 & 29 & - & 11 & 24 & 2 & - & - & - \\
\hline USA & 87 & 77 & 45 & 29 & 28 & 22 & 33 & 2 & 6 & 25 & 3 & 2 & 8 & 1 \\
\hline
\end{tabular}

Table IX Composition of the gallstones from eight countries (symbols as used in Table VI)

\begin{tabular}{|c|c|c|c|c|c|c|c|}
\hline \multirow[t]{2}{*}{ No. of Stones } & \multirow{2}{*}{$\begin{array}{l}\text { Sex or Age } \\
\text { Group }\end{array}$} & \multicolumn{5}{|l|}{ Composition } & \multirow[t]{2}{*}{ Country } \\
\hline & & Cholesterol & $\begin{array}{l}\text { Calcium } \\
\text { Carbonate }\end{array}$ & $\begin{array}{l}\text { Calcium } \\
\text { Phosphate }\end{array}$ & $\begin{array}{l}\text { Calcium } \\
\text { Palmitate }\end{array}$ & Others & \\
\hline $\begin{array}{r}28 \\
9\end{array}$ & $\begin{array}{l}\mathbf{F} \\
\mathbf{M}\end{array}$ & $\begin{array}{l}88 \cdot 4^{*} \\
82 \cdot 4\end{array}$ & $\begin{array}{c}8 \cdot 3^{*} \\
15 \cdot 7\end{array}$ & $\begin{array}{l}0.6 \\
0\end{array}$ & $\begin{array}{l}2.0 \\
1.5\end{array}$ & $\begin{array}{l}0 \cdot 6 \\
0 \cdot 3\end{array}$ & Sweden \\
\hline $\begin{array}{r}41 \\
9\end{array}$ & $\begin{array}{l}\mathbf{F} \\
\mathbf{M}\end{array}$ & $\begin{array}{l}84 \cdot 7^{*} \\
72 \cdot 5\end{array}$ & $\begin{array}{l}11 \cdot 0 \\
13.6\end{array}$ & $\begin{array}{l}1 \cdot 1 \\
0\end{array}$ & $\begin{array}{l}2 \cdot 6 \\
2 \cdot 2\end{array}$ & $\begin{array}{r}0.6 \\
11 \cdot 7\end{array}$ & Germany \\
\hline $\begin{array}{r}13 \\
7\end{array}$ & $\begin{array}{l}\mathbf{F} \\
\mathbf{M}\end{array}$ & $\begin{array}{l}73 \cdot 1^{*} \\
89 \cdot 6\end{array}$ & $\begin{array}{c}23 \cdot 7^{*} \\
0\end{array}$ & $\begin{array}{l}0.6 \\
2.4\end{array}$ & $\begin{array}{l}0.9 \\
3 \cdot 2\end{array}$ & $\begin{array}{l}1 \cdot 7 \\
4 \cdot 8\end{array}$ & Australia \\
\hline $\begin{array}{r}12 \\
6\end{array}$ & $\begin{array}{l}\mathbf{F} \\
\mathbf{M}\end{array}$ & $\begin{array}{l}86.8^{*} \\
56.4\end{array}$ & $\begin{array}{c}2 \cdot 3^{*} \\
21 \cdot 3\end{array}$ & $\begin{array}{r}9 \cdot 5 \\
13 \cdot 4\end{array}$ & $\begin{array}{l}1.4^{*} \\
5 \cdot 1\end{array}$ & $\begin{array}{l}0 \\
3 \cdot 7\end{array}$ & India \\
\hline $\begin{array}{l}62 \\
25\end{array}$ & $\begin{array}{l}\mathbf{F} \\
\mathbf{M}\end{array}$ & $\begin{array}{l}762^{*} \\
68 \cdot 4\end{array}$ & $\begin{array}{l}14 \cdot 2 \\
13 \cdot 7\end{array}$ & $\begin{array}{l}3 \cdot 0^{*} \\
0.2\end{array}$ & $\begin{array}{c}2 \cdot 7^{*} \\
11 \cdot 7\end{array}$ & $\begin{array}{l}3.9 \\
5.9\end{array}$ & USA \\
\hline $\begin{array}{l}28 \\
18\end{array}$ & $\begin{array}{l}\mathbf{F} \\
\mathbf{M}\end{array}$ & $\begin{array}{l}59.4^{*} \\
51.9\end{array}$ & $\begin{array}{l}33 \cdot 6^{*} \\
27 \cdot 3\end{array}$ & $\begin{array}{l}0 * \\
0.8\end{array}$ & $\begin{array}{l}2 \cdot 2 \\
4.0\end{array}$ & $\begin{array}{r}4.9 \\
16.0\end{array}$ & England \\
\hline $\begin{array}{r}26 \\
8\end{array}$ & $\begin{array}{l}\mathbf{F} \\
\mathbf{M}\end{array}$ & $\begin{array}{l}57 \cdot 7^{*} \\
40 \cdot 3\end{array}$ & $\begin{array}{l}13 \cdot 7^{*} \\
26 \cdot 4\end{array}$ & $\begin{array}{l}2 \cdot 4 \\
2 \cdot 8\end{array}$ & $\begin{array}{l}17.8 \\
15.6\end{array}$ & $\begin{array}{r}8.4 \\
14.9\end{array}$ & Kuwait \\
\hline $\begin{array}{r}15 \\
8\end{array}$ & $\begin{array}{l}\mathbf{F} \\
\mathbf{M}\end{array}$ & $\begin{array}{l}57 \cdot 8^{*} \\
14 \cdot 2\end{array}$ & $\begin{array}{l}22 \cdot 4 \\
19 \cdot 8\end{array}$ & $\begin{array}{c}9 \cdot 4^{*} \\
15.6\end{array}$ & $\begin{array}{l}5.9 * \\
37.5\end{array}$ & $\begin{array}{r}4 \cdot 4 \\
12 \cdot 8\end{array}$ & South Africa \\
\hline $\begin{array}{r}234 \\
91\end{array}$ & $\begin{array}{l}\mathbf{F} \\
\mathbf{M}\end{array}$ & $\begin{array}{l}74 \cdot 2^{*} \\
60 \cdot 5\end{array}$ & $\begin{array}{l}15 \cdot 7^{*} \\
17 \cdot 7\end{array}$ & $\begin{array}{l}2.5 \\
2.9\end{array}$ & $\begin{array}{l}4 \cdot 5^{*} \\
9 \cdot 7\end{array}$ & $\begin{array}{l}3 \cdot 1 \\
9 \cdot 1\end{array}$ & All \\
\hline $\begin{array}{l}15 \\
24\end{array}$ & $\begin{array}{l}\leqslant 50 \\
>50\end{array}$ & $\begin{array}{l}81 \cdot 5^{*} \\
90 \cdot 7\end{array}$ & $\begin{array}{c}15.7 * \\
6.5\end{array}$ & $\begin{array}{l}1 \cdot 1^{*} \\
0\end{array}$ & $\begin{array}{l}0.9 \\
2.4\end{array}$ & $\begin{array}{l}0.7 \\
0.3\end{array}$ & Sweden \\
\hline $\begin{array}{l}18 \\
32\end{array}$ & $\begin{array}{l}\leqslant 50 \\
>50\end{array}$ & $\begin{array}{l}83 \cdot 8 \\
81 \cdot 8\end{array}$ & $\begin{array}{l}13 \cdot 3 \\
10 \cdot 4\end{array}$ & $\begin{array}{l}1.9 * \\
0.3\end{array}$ & $\begin{array}{l}0.9 * \\
3.5\end{array}$ & $\begin{array}{l}0 \cdot 2 \\
4 \cdot 0\end{array}$ & Germany \\
\hline $\begin{array}{r}5 \\
14\end{array}$ & $\begin{array}{l}\leqslant 50 \\
>50\end{array}$ & $\begin{array}{l}65 \cdot 0^{*} \\
82 \cdot 3\end{array}$ & $\begin{array}{l}28.3^{*} \\
11.9\end{array}$ & $\begin{array}{l}0 \\
1.8\end{array}$ & $\begin{array}{l}2.2 \\
1.6\end{array}$ & $\begin{array}{l}4 \cdot 4 \\
2 \cdot 4\end{array}$ & Australia \\
\hline $\begin{array}{l}34 \\
34\end{array}$ & $\begin{array}{l}\leqslant 50 \\
>50\end{array}$ & $\begin{array}{l}85 \cdot 1^{*} \\
63 \cdot 6\end{array}$ & $\begin{array}{c}7 \cdot 6^{*} \\
20 \cdot 3\end{array}$ & $\begin{array}{l}3 \cdot 1 \\
2.5\end{array}$ & $\begin{array}{l}3 \cdot 4^{*} \\
9 \cdot 6\end{array}$ & $\begin{array}{l}0.7 \\
3.9\end{array}$ & USA \\
\hline $\begin{array}{l}13 \\
32\end{array}$ & $\begin{array}{l}\leqslant 50 \\
>50\end{array}$ & $\begin{array}{l}56 \cdot 0 \\
57 \cdot 5\end{array}$ & $\begin{array}{l}32 \cdot 2 \\
31 \cdot 5\end{array}$ & $\begin{array}{l}0.9 * \\
0\end{array}$ & $\begin{array}{l}1 \cdot 9 \\
2 \cdot 3\end{array}$ & $\begin{array}{l}9 \cdot 0 \\
8 \cdot 6\end{array}$ & England \\
\hline $\begin{array}{r}29 \\
5\end{array}$ & $\begin{array}{l}\leqslant 50 \\
>50\end{array}$ & $\begin{array}{l}53 \cdot 4 \\
54 \cdot 4\end{array}$ & $\begin{array}{c}19 \cdot 0^{*} \\
3 \cdot 3\end{array}$ & $\begin{array}{l}2 \cdot 9 \\
0\end{array}$ & $\begin{array}{l}16 \cdot 5 \\
22 \cdot 2\end{array}$ & $\begin{array}{r}8 \cdot 2 \\
20 \cdot 0\end{array}$ & Kuwait \\
\hline $\begin{array}{r}4 \\
13\end{array}$ & $\begin{array}{l}\leqslant 50 \\
>50\end{array}$ & $\begin{array}{l}57 \cdot 6^{*} \\
41 \cdot 6\end{array}$ & $\begin{array}{l}13.9 \\
20.3\end{array}$ & $\begin{array}{c}0^{*} \\
10.5\end{array}$ & $\begin{array}{c}3 \cdot 5^{*} \\
22 \cdot 2\end{array}$ & $\begin{array}{r}25 \cdot 0 \\
5 \cdot 3\end{array}$ & South Africa \\
\hline $\begin{array}{l}118 \\
154\end{array}$ & $\begin{array}{l}\leqslant 50 \\
>50\end{array}$ & $\begin{array}{l}71 \cdot 7 \\
69 \cdot 9\end{array}$ & $\begin{array}{l}16 \cdot 1 \\
17 \cdot 1\end{array}$ & $\begin{array}{l}2 \cdot 1 \\
1.7\end{array}$ & $\begin{array}{l}5.7 \\
6.5\end{array}$ & $\begin{array}{l}4 \cdot 4 \\
4.8\end{array}$ & All \\
\hline
\end{tabular}

Table X Percentage composition of stones related to sex and age

*Difference significant. Statistical significance was not tested for compounds under heading 'others'. 
Fig. 3 and subdivided according to the sex and the age of the patients in Table $\mathrm{X}$.

\section{Country}

Comparison of the total weighted amount of material found in each country shows that the composition distribution varies significantly from country to country $(\mathrm{P}<0.001)$. Germany, Sweden, and Australia are the most closely similar countries. The outstanding differences occur in England, Kuwait, and South Africa.

The amount of cholesterol varies considerably. Figure 3 shows a gradual decrease in the amount from $89 \%$ in Sweden to $41 \%$ in South Africa. In all countries except South Africa, cholesterol accounts for more of the stone material than all other crystalline compounds combined. Table X shows that female patients form significantly more cholesterol than do males except in Australia but the prevalence of cholesterol in gallstones could not in general be related to either of the age groups, though variations occur in the different countries. In South Africa only $14 \%$ of the crystalline material from male patients consists of cholesterol accounting for the deficiency of this compound. In this country there is significantly more cholesterol in the younger age group.

Stones from England have significantly more calcium carbonate than stones from any of the other countries ( $P<0.001$ ). Here it accounts for nearly a third of the total crystalline material. This excess occurs in both sexes and both age groups but female patients form significantly more calcium carbonate than males $(\mathrm{P}<0.001)$.

The largest amounts of calcium phosphate are found in South Africa (14\% of the crystalline material) and India (10\%). The findings in these two countries differ significantly from each other $(P<0.02)$ and in each of these two countries the findings differ significantly from all others where only small amounts of calcium phosphate are found $(P<0.001)$. In both South Africa and India both sexes contribute to the excess but in South Africa males form significantly more calcium phosphate than females $(P<0.001)$. In this country calcium phosphate was only found in stones from patients over 50 years of age.
Stones from South Africa and Kuwait have the largest amounts of calcium palmitate: $19 \%$ and $16.5 \%$ of the total composition respectively. These two values are not significantly different from each other $(P>0.05)$ but they do differ significantly from values from all the other countries, where only small amounts of calcium palmitate are found $(P>0 \cdot 001)$. In South Africa the male stone-formers are again responsible for the excess $(P<0.001)$ and significantly more calcium palmitate is found in the older age group $(P<0.001)$. In Kuwait there is no difference in the distribution of this compound with the age or sex of the patients $(P>0.05)$.

\section{Sex and age}

In the subdivisions relating stone composition in the different countries to the sex and to the age of the patient, the number of stones in some of the groups is very small. Any conclusions involving in particular constituents other than cholesterol which under the circumstances are likely to occur in only a few stones should be treated with reservation. Comparison of stone composition with the patient's sex shows that for all the stones there is significantly more cholesterol among female patients and significantly more calcium palmitate and calcium carbonate among males $(\mathrm{P}<0.001)$ (Table X). In the individual countries many significant differences occur. Those which affect the overall composition in a country have already been referred to in the previous section. As mentioned there, female patients form significantly more cholesterol than do males in all countries except Australia. The excess of calcium palmitate among male patients is a result of large contributions from that sex in the USA, South Africa, and to a lesser extent India. In the other countries both sexes form the same amount of calcium palmitate. For all the stones, the distribution of calcium carbonate and calcium phosphate according to the patient's sex does not reflect a consistent pattern in the individual countries.

There is also no consistent pattern for stone composition related to the patient's age for the two groups considered here. The significant differences are given in Table $\mathrm{X}$. The distribution

\begin{tabular}{lllllll}
\hline Sex & Age & No. of Stones & Cholesterol & $\begin{array}{l}\text { Calcium } \\
\text { Carbonate }\end{array}$ & $\begin{array}{l}\text { Calcium } \\
\text { Phosphate }\end{array}$ & $\begin{array}{l}\text { Calcium } \\
\text { Palmitate }\end{array}$ \\
\hline F & $\leqslant 50$ & 92 & 75 & 16 & 2 & 5 \\
F & $>50$ & 104 & 75 & 16 & 2 & 4 \\
M & $\leqslant 50$ & 24 & $65 \frac{1}{2}$ & 17 & $1 \frac{1}{2}$ & 7 \\
M & $>50$ & 48 & 58 & 19 & 1 & 12 \\
\hline
\end{tabular}

Table XI Weighted percentage composition of the gallstones compared with age and sex 
for all the stones shows that the composition in the two age groups is identical.

The individual amounts of calcite, aragonite, and vaterite related to the sex and to the age of the patient differ from country to country. When all the stones are taken together there is significantly more vaterite among female patients $(P<0.001)$, significantly more aragonite formed by males $(P<0.001)$, and significantly more vaterite and less aragonite in the younger age group $(\mathrm{P}<0.001)$.

\section{STONE COMPOSITION RELATED TO BOTH AGE AND SEX}

Table XI, which correlates the stone composition with the patient's age and sex, shows that the pattern of significantly more cholesterol in stones from female patients and significantly more calcium palmitate, amorphous and unidentified material, and slightly more calcium carbonate from male patients found for all the stones irrespective of the patient's age also occurs in the two age groups considered here $(P<0.001)$. There are no differences in the composition of the stones from female patients in these two age groups $(P>0.05)$, but male patients show significant differences of less cholesterol and more calcium palmitate in the older age group (P $<0.001)$.

We thank the Nuffield Foundation for financial support, Dr I. A. D. Bouchier through whose intermediary many of the stones were obtained,
Dr E. Hoff for writing the computer program for the IBM 360, Mrs J. Fedrick for advice with the statistics, and $\mathrm{Mr} \mathrm{R}$. Henriques for the chi-square program for Pegasus.

The people who supplied the gallstones and to whom we are grateful for making this study possible are Professor M. R. Ewing and Dr M. Wheeler (Australia); Professor A. J. Harding Rains and Mr C. J. C. Kirk (England); Dr C. Wolpers (Germany); Dr S. L. Malhotra (India); Dr S. N. Salem (Kuwait); Dr D. J. du Plessis (South Africa); Dr W. van der Linden (Sweden); and Dr T. Dawber, Dr F. Glenn, and Dr L. Shoenfield (USA).

\section{References}

Bogren, H. (1964). The composition and structure of human gallstones. Acta radiol. (Stockh.), Suppl., 226.

Bogren, H., and Larsson, K. (1963). An X-ray diffraction study of crystalline cholesterol in some pathological deposits in man. Biochim. biophys. Acta (Amst.), 75, 65-69.

Carr, J. A. (1953). The pathology of urinary calculi: radial striation. Brit. J. Urol., 25, 26-32.

Lonsdale, K. (1968). Epitaxy as a growth factor in urinary calculi and gallstones. Nature (Lond.), 217, 56-58.

Nakayama, F. (1968). Quantitative microanalysis of gallstones. J. Lab. clin. Med., 72, 602-611.

Raha, P. K., Sengupta, K. P., and Aikat, B. K. (1966). X-ray diffraction analysis of gallstones. Indian J. med. Res., 54, 729-734.

Sutor, D. J. (1970). Calcium palmitate and $\alpha$-palmitic acid in gallstones. Gut, 11, 618-619.

Sutor, D. J., and Scheidt, S. (1968). Identification standards for human urinary calculus components, using crystallographic methods. Brit. J. Urol., 40, 22-28.

Sutor, D. J., and Wooley, S. E. (1969). $X$-ray diffraction studies of the composition of gallstones from English and Australian patients. Gut, 10, 681-683. 